\title{
A pipa sem varetas no estado de São Paulo: variação diatópica
}

DOl: http://dx.doi.org/10.21165/el.v50i3.3031

\author{
Beatriz Aparecida Alencar ${ }^{1}$
}

\section{Resumo}

Os jogos e as diversões são elementos presentes nas diferentes culturas e o modo de nomear esses objetos acabam por refletir a relação entre o homem, o brinquedo e a sociedade. Desse modo, este estudo examina as denominações cartografadas para a pipa sem varetas na tese O Léxico de Brinquedos e Brincadeiras infantis no estado de São Paulo (ALENCAR, 2018), com vistas a delimitar geograficamente os registros de capucheta, denominação mais produtiva, buscando comprovar sua presença como uma marca paulista no léxico dos brinquedos. Com esse propósito, se discutem as denominações obtidas para esse brinquedo em comparação com outros trabalhos. A tese base para o estudo foi produzida a partir de dados do Projeto ALiB e contou com uma rede de 47 localidades nos estados de SP, PR, MG, MS, RJ totalizando na análise de 188 inquéritos. O estudo pautou-se em pressupostos da Dialetologia, da Lexicologia e da Etnolinguística.

Palavras-chave: Dialetologia; São Paulo; Projeto ALiB; jogos e diversões infantis; capucheta.

1 Instituto Federal de Mato Grosso do Sul (IFMS), Campo Grande, Mato Grosso do Sul, Brasil; beatriz.alencar@ifms.edu.br; https://orcid.org/0000-0002-3559-6559 


\section{El cometa sin varetas en el estado de São Paulo: variación diatópica}

\section{Resumen}

Los juguetes y diversiones infantiles son elementos presentes en la sociedad y la forma de nombrar los objetos acaba por reflejar la relación entre hombre, juguete y cultura. Así, este estudio busca analizar las denominaciones cartografiadas para cometa sin vareta en la tesis O Léxico de Brinquedos e Brincadeiras infantis no estado de São Paulo (ALENCAR, 2018), buscando delimitar geográficamente los registros de capucheta, nombre más productivo, con el objetivo de comprobar su presencia como una palabra específica del léxico de los juguetes. Con ese propósito, también se discuten los nombres obtenidos para el juguete en comparación con otros trabajos dialectales. La tesis fue producida a partir de datos del Proyecto ALiB y contó con una red de puntos de 47 localidades en los estados de SP, PR, MG, MS, RJ totalizando en el análisis de 188 entrevistas. El estudio está basado en estudios de la Dialectología, Lexicología y Etnolingüística.

Palabras-Ilave: Dialectología; São Paulo; juguetes y diversiones infantiles; columpio; Proyecto ALiB.

\section{Introdução: apresentação do objeto e área de estudo}

Os brinquedos e as diversões infantis são elementos de uma cultura que marcam diferentes gerações e povos, deixando suas contribuições no decorrer dos tempos. Para alguns indivíduos, os brinquedos podem ser vistos como meros objetos, porém para outros, como salientado por Benjamin (2009, p. 12), pode ser um instrumento que faz parte das memórias afetivas e que traz várias lembranças: "[...] Mas quando um poeta moderno diz que para cada um existe uma imagem em cuja contemplação o mundo inteiro submerge, para quantas pessoas essa imagem não se levanta de uma velha caixa de brinquedos".

A reflexão de Benjamin (2009) nos remete ao modo como a mente humana pode significar o valor do brincar, que vai além das subjetividades, perpassa gerações e pode deixar vestígios na cultura de uma sociedade. Essas marcas podem atingir diferentes segmentos, entre eles, o repertório próprio de um povo e, consequentemente, os modos de falar e de nomear os objetos a sua volta, pois, "[...] o léxico de uma língua constitui uma forma de registrar o conhecimento do universo" (BIDERMAN, 1998, p. 91).

Haja vista a importância do léxico na história dos povos em diferentes épocas e a relevância dos entretenimentos infantis como representativo das particularidades lexicais da cultura de uma determinada população, este estudo busca contribuir para a descrição do vocabulário dos jogos e diversões infantis no estado de São Paulo, com vistas a permitir maior conhecimento sobre essa área semântica na região assinalada. 
Para tanto, este trabalho analisará as denominações cartografadas na tese 0 Léxico de Brinquedos e Brincadeiras infantis no estado de São Paulo² (ALENCAR, 2018) no que se refere às denominações para a "pipa" (sem varetas) ${ }^{3}$, nas 47 localidades que constituem a rede de pontos da pesquisa. Esses dados são de natureza dialetal e, ao examiná-los, intentase realizar [...] "uma investigação de cunho horizontal, ou seja, busca-se uma fotografia da realidade nos espaços geográficos considerados" (CARDOSO, 2010, p. 12). Portanto, a análise proposta se debruçará, prioritariamente, na discussão dos dados diatópicos no que se refere à questão analisada.

Este estudo tem como intuito discutir as quatro variantes cartografadas na área selecionada pela tese, buscando identificar se a denominação mais produtiva no estado investigado, capucheta, é um modo próprio dos paulistas para nomear a pipa sem varetas. Com este propósito, também será verificado se a ocorrência dessa unidade lexical atinge territórios que vão além das fronteiras geográficas do estado de São Paulo. Nesse sentido, contribuirão para esta análise os estudos que também examinaram os dados coletados pelo Projeto ALiB sobre os entretenimentos infantis em regiões imediatas ao território paulista ${ }^{4}$, são eles: a dissertação de mestrado Brincando pelos caminhos do falar fluminense (SANTOS, 2016) e a monografia de especialização Registrando o léxico dos brinquedos e brincadeiras infantis em Minas Gerais (D'ANUNCIAÇÃO, 2016). Ainda buscando verificar as delimitações geográficas do uso de capucheta, pretende-se consultar outros trabalhos produzidos sobre o léxico dos Jogos e Diversões Infantis com dados do projeto nacional que recobrem outras regiões do Brasil (RIBEIRO, 2012; PORTILHO, 2013; SANTOS, 2018). Como fruto, esta discussão busca proporcionar a apuração e/ou confırmação de uma possível isoléxica no estado de São Paulo ou para além das fronteiras com as ocorrências de capucheta e analisar possíveis motivações para as respostas indicadas no estudo. Como pressupostos teóricos, o estudo baseia-se em fundamentos da Dialetologia (CARDOSO, 2010); da Lexicologia (BIDERMAN, 1998) e da Etnolinguística (SAPIR, 1969).

Quanto aos dados que serão utilizados como base deste estudo, cabe informar que a tese de Doutorado O Léxico de Brinquedos e Brincadeiras infantis no estado de São Paulo (ALENCAR, 2018) foi produzida no Programa de Pós-Graduação em Letras da Universidade Federal de Mato Grosso do Sul, sob a orientação da professora Dra. Aparecida Negri Isquerdo. O trabalho acadêmico foi produzido a partir de dados coletados no interior

\section{0 trabalho é um recorte da tese da autora.}

3 A tese foi produzida a partir dos dados coletados pelo Projeto Atlas Linguístico do Brasil. Neste particular, foram analisados os resultados apontados por Alencar (2018) como resposta para a pergunta 159 do Questionário Semântico-Lexical do Projeto ALiB: "Como se chama um brinquedo parecido com a pipa, também feito de papel, mas sem varetas, que se empina ao vento pode meio de uma linha?" (COMITÊ NACIONAL DO PROJETO ALIB, 2001, p. 34).

4 Em todos os trabalhos citados, foram verificados os dados cartografados e/ou analisados para a pergunta 159/QSL/ALiB. 
de São Paulo, pela equipe do Projeto Atlas Linguístico do Brasil (ALiB) entre os anos de 2001 e 20085. Portanto, para a seleção dos informantes seguem-se as características preconizadas pelo projeto nacional: 6 i) sexo: masculino e feminino; ii) faixas etárias I: 1830 anos e II: 50-65 anos e; iii) escolaridade: fundamental incompleto. Dessa maneira, o corpus foi constituído pelas respostas fornecidas por 188 entrevistados, de ambos os sexos, de duas faixas etárias, com ensino fundamental incompleto e computando o número de quatro por localidade.

Quanto às localidades investigadas, foram considerados os 37 pontos de inquéritos do interior do estado de São Paulo e acrescidas 10 localidades denominadas de área de controle. Essa nomenclatura é utilizada em Ribeiro (2012) e, no estudo analisado, busca controlar as respostas fornecidas pelos informantes nos pontos ALiB situados próximos às imediações do estado de São Paulo. Sendo assim, foram incluídos: um ponto de inquérito do estado de Mato Grosso do Sul, quatro de Minas Gerais, três do Paraná e duas do Rio de Janeiro.

Quanto ao objeto analisado, a capucheta, segundo o site Mapa do Brincar (2018), pode ser classificado na categoria da pipa. Porém, diferente da pipa convencional, ela é produzida de forma bastante simples e, muitas vezes, com uma folha de papel. Entre suas principais características, destaca-se o fato de que o brinquedo não atinge muita altura durante seus breves voos.

Na sequência, discutem-se as denominações obtidas para "um brinquedo parecido com a pipa, também feito de papel, mas sem varetas, que se empina ao vento por meio de uma linha?"7 no estado de São Paulo.

\section{Pipa sem varetas: produtividade das variantes cartografadas/dados analisados}

A pergunta analisada no território paulista foi bastante produtiva com um quantitativo de 187 ocorrências. Tendo em vista o alto número de respostas, as denominações foram agrupadas considerando as características similares em termos fonéticos e morfológicos. Como resultado, 13 variantes lexicais foram apresentadas: capucheta, pipa, papagaio, cartola, maranhão, balão, aviãozinho, arraia, papa-vento, cuíca, jereco, rabiola, sapim. Dentre elas, capucheta foi a resposta mais produtiva para nomear o brinquedo em questão no estado de São Paulo. No Quadro 1, a seguir, apresentam-se as variantes lexicais e respectivos agrupamentos.

$5 \mathrm{Na}$ área de controle, os inquéritos variam entre os anos de 2002 e 2013.

6 Para mais informações sobre metodologia do trabalho, sugere-se a consulta em: https://alib. ufba.br/content/transcritores e https://alib.ufba.br/content/rede-de-pontos.

70 texto da pergunta refere-se à questão 159 do questionário semântico-lexical do Projeto ALiB. 
Quadro 1. Agrupamentos de variantes lexicais para "um brinquedo parecido com a pipa, também feito de papel, mas sem varetas, que se empina ao vento por meio de uma linha"

\begin{tabular}{|c|c|}
\hline Variações lexicais & Itens agrupados \\
\hline Capucheta & $\begin{array}{r}\text { Cabucheta, cacheta, cachetinha, cachuleta, capuche, capucheta, } \\
\text { capuchetinha, capuchieta, capuchinha, capucho, cartucheta, } \\
\text { catuchepa, catuchera, encapucheta, }\end{array}$ \\
\hline Pipa & Pipa, pipinha \\
\hline Papagaio & Papagaio, papagai \\
\hline Cartola & Cartola, cartolinha \\
\hline Maranhão & Maranhão \\
\hline Balão & Balão, balãozinho \\
\hline Aviãozinho & Aviãozinho \\
\hline Arraia & Arraia, raia \\
\hline Papa-vento & Papa-vento, cata-vento \\
\hline Cuíca & Cuíca \\
\hline Jereco & Jereco \\
\hline Rabiola & Rabiola \\
\hline Sapim & Sapim \\
\hline ocorrências únicas & Peixinha, gamelão, prancheta \\
\hline
\end{tabular}

Fonte: Alencar (2018, p. 438)8

No quadro 1, ainda foram registradas três denominações indicadas como ocorrências únicas (peixinha, gamelão, prancheta). Com base na produtividade da pergunta, foram produzidos quadros e cartas no trabalho em estudo. Veja o gráfico 1 que indica a produtividade das denominações para capucheta no estado de São Paulo.

8 Cabe salientar que a reprodução de alguns quadros e gráficos são de Alencar (2018), por sua vez, a autora informa que esses materiais foram produzidos com base nos dados do Projeto ALiB. 
Gráfico 1. Produtividade da denominação capucheta no estado de São Paulo

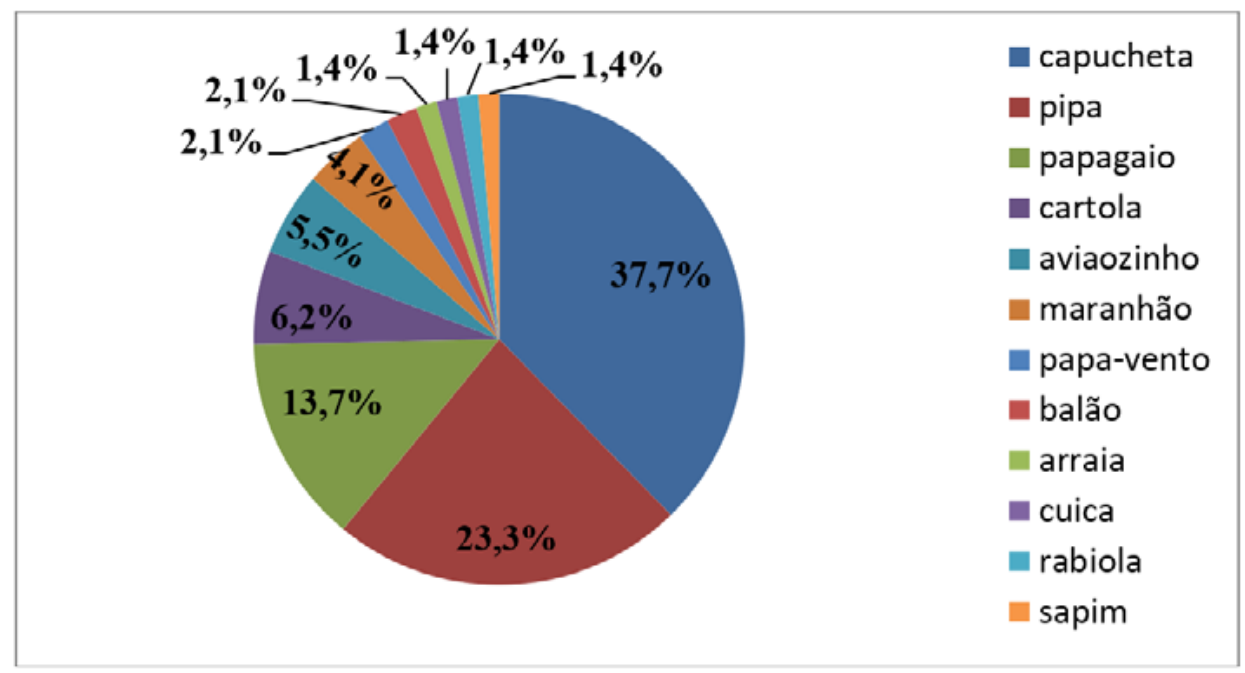

Fonte: Alencar (2018, p. 439)

No gráfico 1, nota-se a superioridade de capucheta como designativo para pipa sem varetas, seguida das denominações pipa $(23,3 \%)$ e papagaio $(13,7 \%)$. Por sua vez, ao verificar os pontos de inquéritos limítrofes ao estado de São Paulo, capucheta continua sendo produtiva, porém com menor percentual de registro, conforme pode ser visto no gráfico 2:

Gráfico 2. Produtividade da denominação capucheta na área de controle

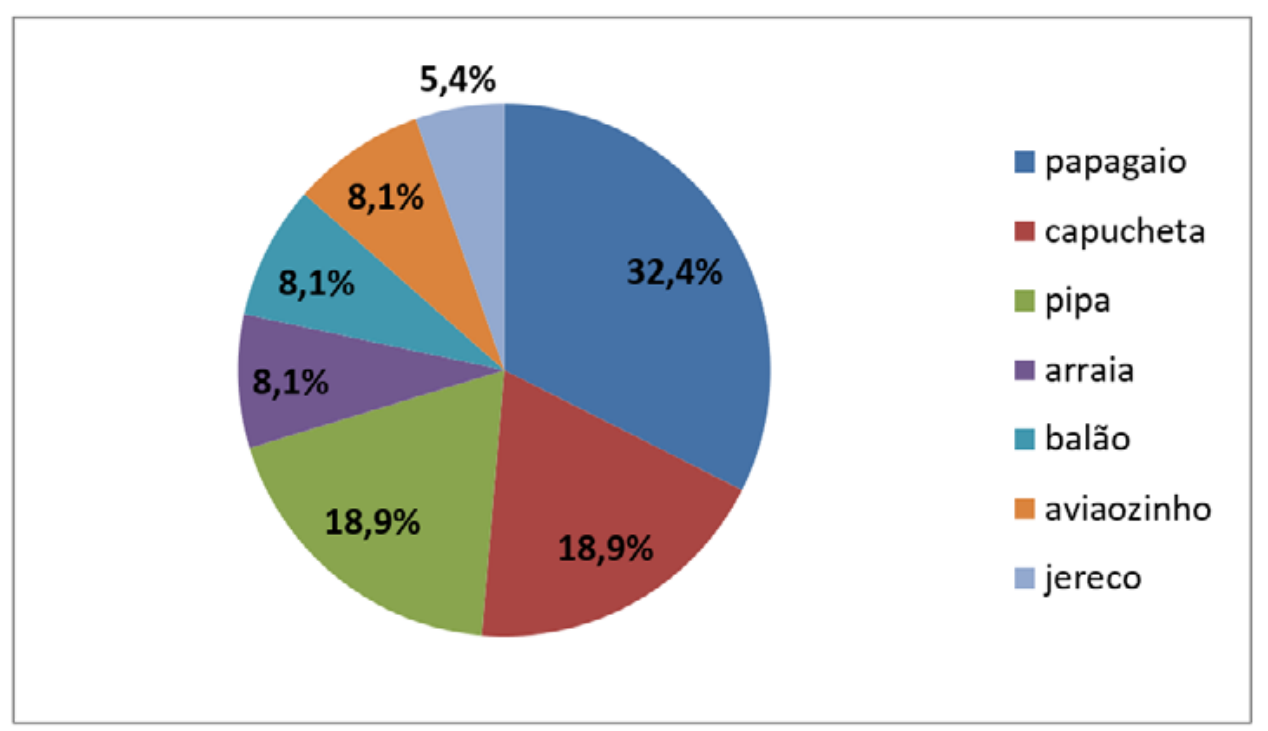

Fonte: Alencar (2018, p. 441) 
O gráfıco 2 indica que a unidade lexical papagaio figura como denominação mais produtiva na área de controle, sendo seguida por capucheta e pipa, que registram mesmo percentual de ocorrências (18,9\%). No que tange à produtividade da pergunta, Alencar (2018) ainda produz duas cartas linguísticas indicadas como 11a (Denominações para capucheta no estado de São Paulo) e 11b (Denominações para capucheta na área de controle). Ao observar as cartas, é possível produzir o quadro 2, que informa as ocorrências das denominações cartografadas nos estados que compõem a região investigada no estudo.

Quadro 2. Respostas cartografadas no estado de São Paulo e áreas de controle

\begin{tabular}{|c|c|c|c|c|c|}
\hline Item lexical & São Paulo & \multicolumn{4}{|c|}{ Área de controle } \\
\hline & Interior & MS & MG & PR & RJ \\
\hline Capucheta & $X$ & & $X$ & $X$ & \\
\hline Pipa & $X$ & $X$ & $X$ & $X$ & \\
\hline Papagaio & $X$ & & $X$ & $X$ & $X$ \\
\hline Aviãozinho & $X$ & & & & \\
\hline Arraia & & & & & $X$ \\
\hline
\end{tabular}

Fonte: Elaboração própria

De acordo com o quadro 2, é possível afirmar que capucheta ocorre no estado de São Paulo e também em pontos de inquéritos de dois estados vizinhos. Quanto à área de controle, em Mato Grosso do Sul, a unidade lexical pipa é registrada como única denominação fornecida como resposta; em Minas Gerais, pipa ocorre junto com papagaio e capucheta. No Paraná, predomina o uso da denominação pipa seguida por papagaio. Segundo Alencar (2018, p. 380), na área de controle, [...] "há manutenção das três denominações mais produtivas, porém de formas distintas, pois papagaio ocupa a primeira posição em termos de número de ocorrências".

Após o exame da produtividade das denominações para a "pipa sem varetas" nas localidades investigadas, serão detalhados os aspectos diatópicos referentes às denominações obtidas, com destaque para as unidades léxicas cartografadas no estado de São Paulo.

\section{Análise diatópica das denominações para "capucheta" cartografadas}

Na continuação, serão examinadas as denominações cartografadas em Alencar (2018) que apresentam as quatro respostas mais produtivas fornecidas pelos informantes. As denominações serão analisadas de acordo com a produtividade de cada variante, em ordem decrescente, com destaque para os dados obtidos no estado de São Paulo. 


\section{capucheta}

A unidade lexical capucheta foi a mais produtiva (38\%) para a pergunta analisada e foi citada por falantes de ambos os sexos e faixas etárias na maioria dos pontos de inquérito do estado de São Paulo. Entre as mesorregiões paulistas, pode-se afirmar que capucheta foi mais produtiva em Presidente Prudente e na região Metropolitana de São Paulo. Essas mesorregiões marcam dois pontos limítrofes do estado. Ainda cabe informar que há localidades com o uso exclusivo de capucheta para nomear a pipa sem varetas, por exemplo, Mococa (ponto 160), Araraquara (163) e Marília (166)9. Já o não registro de capucheta foi identificado apenas na Mesorregião de Assis.

$\mathrm{Na}$ área de controle, o item lexical capucheta foi documentado apenas nos estados do Paraná e Minas Gerais.

Na sequência, discutem-se os dados relativos à unidade lexical pipa.

\section{pipa}

O item lexical pipa tem produtividade significativa no estado de São Paulo (23\%) ocorrendo em diferentes localidades, de diferentes mesorregiões. Com destaque para a mesorregião de Itapetininga pelo alto número de ocorrências e ausência na mesorregião de Marília.

$\mathrm{Na}$ área de controle, pipa é indicada como denominação produtiva com o mesmo percentual de ocorrência de capucheta (19\%), sendo registrada em Mato Grosso do Sul (forma única) e, no Paraná e em Minas Gerais, com três registros em cada unidade federativa.

A seguir, discutem-se os dados obtidos para papagaio.

\section{papagaio}

A unidade lexical papagaio foi registrada em diferentes regiões do estado de São Paulo, computando um percentual de $14 \%$. Em boa parte das localidades, registrou baixa ocorrência, atingindo maiores índices nas mesorregiões de Itapetininga e Ribeirão Preto e ausência nas mesorregiões de: Campinas, Marília e Piracicaba.

9 Considerando os dados da capital paulista cartografados no Atlas Linguístico do Brasil, na carta L21 (CARDOSO et al., 2014, p. 303) informa-se que a unidade lexical capucheta é a única reposta fornecida pelos moradores da cidade de São Paulo. 
Quanto à área de controle, papagaio foi documentado nos estados de Minas Gerais (três localidades), no Paraná (duas localidades) e no Rio de Janeiro figurou como resposta em todos os pontos de inquérito.

Na continuação, são discutidos os dados diatópicos relativos ao item lexical aviãozinho.

\section{aviãozinho}

A denominação aviãozinho foi documentada em localidades do estado de São Paulo, sendo fornecida como resposta em cinco mesorregiões paulistas, são elas: Bauru, Itapetininga, Litoral Sul Paulista, Presidente Prudente e Vale do Paraíba Paulista.

Quanto à área de controle, aviãozinho foi registrada em Minas Gerais com uma ocorrência e no Paraná com duas ocorrências em dois pontos de inquéritos distintos.

Na sequência, discute-se a produtividade das denominações considerando os diferentes perfis dos informantes.

\section{Dimensões diassexuais e diageracionais das variantes cartografadas}

Neste tópico, busca-se discutir as denominações obtidas para a pipa sem varetas, de acordo com os critérios sociais controlados pelas coletas realizadas pela equipe do Projeto ALiB. A importância do controle da variação diassexual e diageracional aos trabalhos que buscam registrar a variação geográfica se mostra como: "[...] uma resposta a exigências da nova configuração de que se reveste o mundo atual. E a geolinguística, ao adotar outros parâmetros que não o diatópico, está, apenas, respondendo aos apelos da realidade atual" (CARDOSO, 2010, p. 63-64).

No que tange às denominações documentadas para o brinquedo sem varetas, pontuase que a denominação capucheta foi mais produtiva na fala do informante do sexo masculino, faixa etária I. Já as demais denominações são mais frequentes nas falas dos informantes mais idosos: sendo que pipa ocorre com maior percentual na fala das informantes do sexo feminino; papagaio com expressiva preferência entre as mulheres da faixa etária II e aviãozinho pelos homens mais idosos. Essas informações podem ser visualizadas na tabela 1. 
Tabela 1. Realização das denominações para pipa sem varetas considerando as variáveis sexo e idade

\begin{tabular}{c|c|c|c|c}
\cline { 2 - 5 } & \multicolumn{2}{|c|}{ Faixa etária I } & \multicolumn{2}{c}{ Faixa etária II } \\
\hline Sexo & Masculino & Feminino & Masculino & Feminino \\
\hline Capucheta & $37,70 \%$ & $24,60 \%$ & $23,20 \%$ & $14,50 \%$ \\
\hline Pipa & $14,66 \%$ & $26,82 \%$ & $26,82 \%$ & $31,70 \%$ \\
\hline Papagaio & $0 \%$ & $9,5 \%$ & $37,5 \%$ & $53 \%$ \\
\hline Aviãozinho & $0 \%$ & $27,5 \%$ & $45 \%$ & $27,5 \%$ \\
\hline
\end{tabular}

Fonte: Elaboração própria

Conforme a tabela 1, nota-se que, por um lado, as realizações de capucheta são mais produtivas na fala dos informantes do sexo masculino, possivelmente por estar mais presente nos entretenimentos realizados por meninos. Por outro lado, o uso de capucheta é documentado em todas as faixas etárias investigadas, com percentuais consideráveis, o que aponta para certa vitalidade da denominação entre a população. Quanto às ocorrências de pipa, estão em todas as faixas etárias, porém com menor índice entre os informantes do sexo masculino, faixa etária I. Esse cenário pode indicar possível dificuldade pelo entrevistado mais jovem em diferenciar a pipa com ou sem varetas, ou ainda, a marca de uma denominação antiga para nomear o referente em questão.

Essa situação se acentua no exame das ocorrências de papagaio, pois não foi registrada entre os informantes mais jovens do sexo masculino. Já entre os mais idosos, alçou o percentual de $90,5 \%$ das ocorrências, o que pode denotar certo conservadorismo na forma de nomear o brinquedo ${ }^{10}$. Quanto à denominação aviãozinho, é apresentada como preferência na fala de entrevistados do sexo masculino. Essa resposta pode ser fornecida por desconhecimento das peculiaridades do brinquedo ou ainda por uma forma própria de nomear o objeto por esses informantes.

Após a análise da variação diatópica, diassexual e diageracional das denominações registradas no estado de São Paulo, passaremos para a apresentação dos trabalhos dialetais produzidos nas áreas vizinhas ao estado paulista e a discussão dos dados apontados.

10 Assim como pipa, a denominação papagaio também pode denotar possível dificuldade do informante em diferenciar a pipa com ou sem varetas. 


\section{Trabalhos dialetais produzidos nas imediações paulistas: o falar fluminense e as Minas Gerais}

A dissertação de mestrado Brincando pelos caminhos do falar fluminense (SANTOS, 2016) e a monografia de especialização Registrando o léxico dos brinquedos e brincadeiras infantis em Minas Gerais (D'ANUNCIAÇÃO, 2016) foram produzidas no Programa de PósGraduação em Língua e Cultura da Universidade Federal da Bahia, sob orientação da professora Dra. Silvana Soares Costa Ribeiro ${ }^{11}$. Além disso, os trabalhos analisaram a área temática dos Jogos e Diversões Infantis e foram estruturados a partir do banco de dados do Projeto Atlas Linguístico do Brasil. A seguir, apresentam-se as pesquisas e os resultados obtidos pelos estudos, considerando o objetivo deste artigo. A análise será iniciada pela exposição dos dados da dissertação.

\section{Brincando pelos caminhos do falar fluminense (SANTOS, 2016)}

A dissertação examinou as respostas obtidas para as 13 perguntas da área semântica Jogos e Diversões Infantis, do Questionário Semântico-Lexical do Projeto ALiB em 35 pontos de inquéritos, localizados nos estados de: Bahia, Minas Gerais, São Paulo, Espírito Santo e Rio de Janeiro, sendo que nove localidades pertencem à área de controle. Sendo assim, foram analisados 148 inquéritos. Os dados obtidos receberam tratamento estatístico (frequência por número de ocorrências e o uso de tabelas e gráficos) além da cartografação das denominações.

No que se refere aos dados obtidos para a "pipa sem varetas", as denominações mais produtivas são papagaio e pipa. Quanto à presença de capucheta, consta apenas com quatro registros em todo o universo da pesquisa, o que computou em $3 \%$ do total relativo. Essas ocorrências foram registradas nos estados de São Paulo e Minas Gerais. Esses pontos são coincidentes aos indicados pelo estudo paulista (ALENCAR, 2018).

Em relação às denominações mais produtivas no estudo do falar fluminense, respectivamente papagaio e pipa, verificou-se que estão distribuídas nos diferentes estados investigados no estudo. Essa informação pode ser visualizada no quadro 3 :

110 trabalho Brincando pelos caminhos do falar fluminense (SANTOS, 2016) foi coorientado pela professora Dra. Marcela Moura Torres Paim. 
Quadro 3. Respostas cartografadas na área do falar fluminense e áreas de controle

\begin{tabular}{|c|c|c|c|c|c|c|c|c|}
\hline \multirow{2}{*}{ Item lexical } & \multicolumn{4}{|c|}{ Falar fluminense } & \multicolumn{3}{c|}{ Área de controle } \\
\cline { 2 - 10 } & Nordeste & \multicolumn{4}{|c|}{ Sudeste } & \multicolumn{3}{c|}{ Sudeste } \\
\cline { 2 - 10 } & BA & ES & MG & SP & RJ & MG & SP & RJ \\
\hline Papagaio & $X$ & $X$ & $X$ & $X$ & $X$ & & & \\
\hline Pipa & $X$ & $X$ & $X$ & $X$ & $X$ & & & \\
\hline Aviãozinho & & & & & & $X$ & $X$ & $X$ \\
\hline Arraia & & $X$ & $X$ & & $X$ & & & \\
\hline Capucheta & & & & & & $X$ & $X$ & \\
\hline
\end{tabular}

Fonte: Elaboração própria com base em Santos (2016)

Conforme o quadro 3, fica evidente que a denominação capucheta ocorre apenas na área de controle, assim como aviãozinho. Por sua vez, denominações como papagaio e pipa mostram-se as mais produtivas no estudo de Santos (2016), sendo documentada em todos os estados que compõem a região do falar fluminense.

Na continuação, discutem-se os dados da monografia produzida sobre o léxico dos brinquedos em Minas Gerais.

\section{Registrando o léxico dos brinquedos e brincadeiras infantis em Minas Gerais (D'ANUNCIAÇÃO, 2016)}

O trabalho analisou as respostas obtidas para cinco perguntas da área semântica dos Jogos e Diversões infantis do Questionário Semântico-Lexical do Projeto ALiB, respectivamente as questões 156 (bolinha de gude), 157 (estilingue), 158 (pipa com vareta), 159 (pipa sem vareta) e 167 (amarelinha) nos 23 pontos de inquéritos de Minas Gerais, totalizando 96 inquéritos. A pesquisa apresenta a variação diatópica observada no estado investigado, considerando o léxico dos brinquedos e brincadeiras infantis a partir de gráficos e cartogramas.

No que concerne aos dados obtidos para a questão em estudo, verifica-se que as denominações papagaio e pipa foram as respostas mais produtivas em Minas Gerais. Quanto ao registro de capucheta, registrou-se um percentual de 6,5\% das ocorrências em três localidades mineiras, são elas: Passos (ponto 140), Poços de Caldas (ponto 147) e Itajubá (ponto 149).

Ao observar os dados examinados na monografia dos brinquedos no estado de Minas Gerais, verifica-se que os casos de capucheta repetem os mesmos pontos de inquérito do estudo de Alencar (2018). Ou seja, não houve acréscimo de nenhuma outra localidade 
com a documentação dessa denominação, apesar de a rede de pontos do estudo englobar todo o estado de Minas Gerais.

Desse modo, ao analisar os três trabalhos dialetais realizados com base nos dados do Projeto Atlas Linguístico do Brasil, constatou-se que diferentes denominações foram indicadas como resposta para "um brinquedo parecido com a pipa, também feito de papel, mas sem varetas, que se empina ao vento por meio de uma linha?" (COMITÊ NACIONAL DO PROJETO ALiB, 2001, p. 34). Entre elas, as unidades léxicas papagaio, pipa e arraia12 foram elencadas em todos os trabalhos, inclusive com alta produtividade. Veja o quadro 4, que indica a realização de todas as denominações cartografadas nos três estudos. ${ }^{13}$

Quadro 4. Quadro síntese das variantes cartografadas nos trabalhos analisados

\begin{tabular}{|c|c|c|c|}
\hline $\begin{array}{c}\text { Denominações } \\
\text { cartografadas }\end{array}$ & $\begin{array}{c}\text { Brincando pelos } \\
\text { caminhos do } \\
\text { falar fluminense } \\
\text { (SANTOS, 2016) }\end{array}$ & $\begin{array}{c}\text { Registrando o léxico } \\
\text { dos brinquedos e } \\
\text { brincadeiras infantis } \\
\text { em Minas Gerais } \\
\text { (D'ANUNCIAÇÃO, 2016) }\end{array}$ & $\begin{array}{c}\text { O Léxico de brinquedos } \\
\text { e brincadeiras infantis } \\
\text { no estado de São } \\
\text { Paulo (ALENCAR, } \\
\text { 2018) }\end{array}$ \\
\hline Papagaio & $X$ & $X$ & $X$ \\
\hline Pipa & $X$ & $X$ & $X$ \\
\hline Arraia/ raia & $X$ & $X$ & $X$ \\
\hline Gereco/ jereco & $X$ & $X$ & $X$ \\
\hline Avião/aviãozinho14 & $X$ & $X$ & \\
\hline Balão & $X$ & $X$ & \\
\hline Caixote/caixeta & $X$ & $X$ & \\
\hline Capucheta/capuxeta & $X$ & & \\
\hline Ratinho/ratinha & $X$ & $X$ & \\
\hline Papa-vento & $X$ & & \\
\hline Pião & $X$ & & \\
\hline Arara & & & \\
\hline
\end{tabular}

Fonte: Elaboração própria ${ }^{15}$

12 Indicada como raia ou arraia a depender do trabalho.

13 Além das denominações que compõem o quadro 4, ainda foram indicadas outras respostas que não foram cartografadas a depender do critério adotado para a cartografação dos dados de cada um dos trabalhos elencados. As demais variantes registradas podem ser conhecidas nos trabalhos referenciados.

14 Indicada como avião ou aviãozinho a depender do trabalho.

15 Elaboração própria com base nos trabalhos referenciados. 
Ao verificar o quadro 4, pontua-se que várias denominações se repetem nas diferentes pesquisas em regiões limítrofes ao estado de São Paulo, sendo que algumas são frutos dos pontos de inquéritos comuns entre os trabalhos e, outros, registrados em localidades distintas. Além disso, pontua-se que há uma tendência em nomear a pipa sem varetas com nomes que se relacionam aos animais (formas zoomórficas).

Diante da reflexão aqui proposta, conclui-se que a denominação capucheta comprova-se como uma forma própria de nomear "um brinquedo parecido com a pipa, também feito de papel, mas sem varetas, que se empina ao vento por meio de uma linha" no estado de São Paulo. Nota-se que, mesmo em trabalhos realizados em áreas limítrofes a partir de um mesmo questionário, com uma mesma equipe para as coletas de dados, não foi documentado o uso de capucheta em localidades diferentes das registradas na área de estudo delimitada para o trabalho o léxico de brinquedos e brincadeiras infantis no estado de São Paulo (ALENCAR, 2018). Na sequência, é possível visualizar a figura 1, que ilustra as ocorrências de capucheta no estado de São Paulo e na área de controle (Veja a figura 1).

Figura 1. Indicação das localidades com registro de capucheta nas áreas investigadas

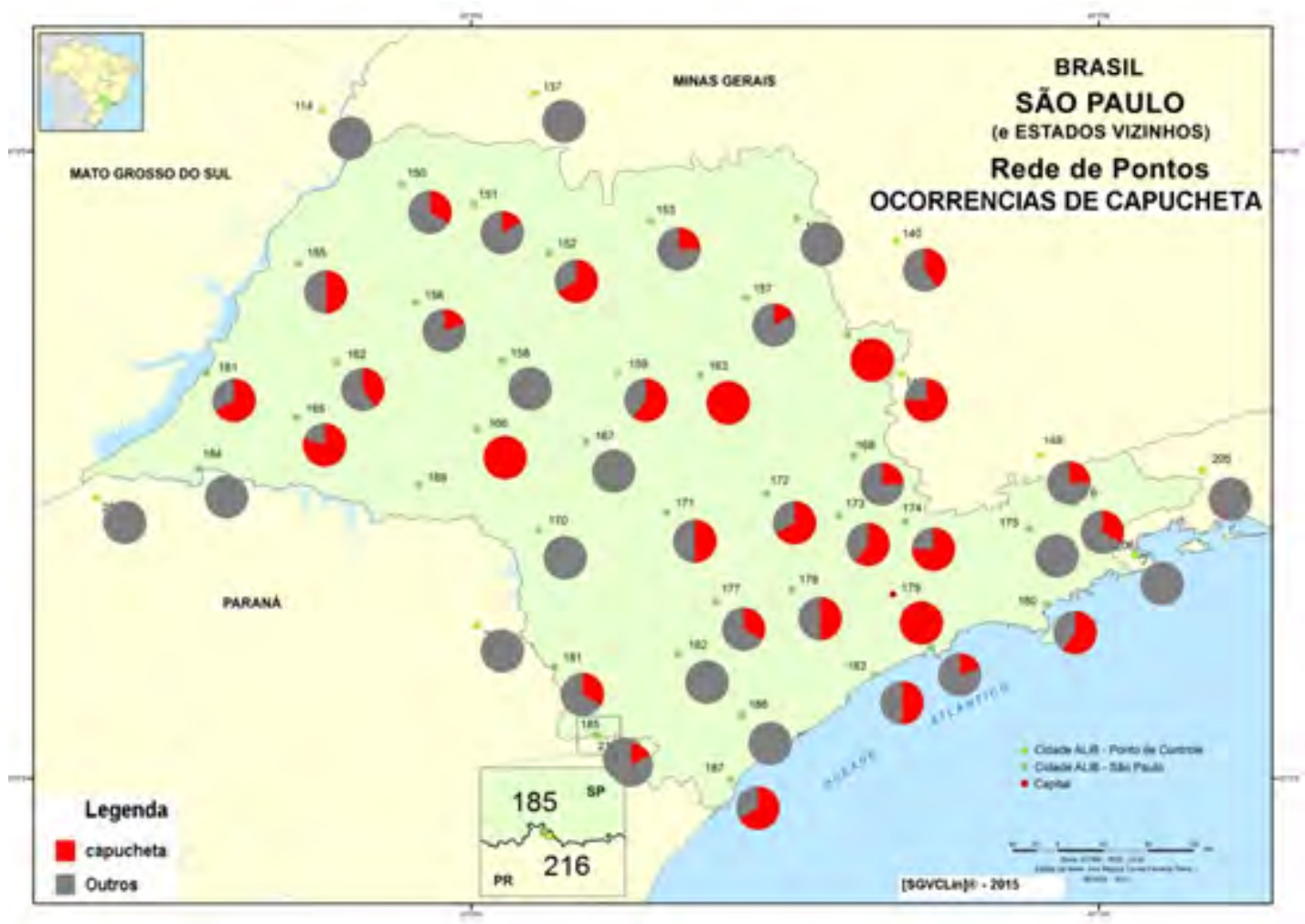

Fonte: Alencar (2018, p. 508) 
Ao visualizar a figura 1, após realizar as análises de Santos (2016) e D’Anunciação (2016), confirma-se a ocorrência de capucheta apenas no território investigado em Alencar (2018). Assim como salientado no estudo paulista, corrobora-se a presença de capucheta como uma marca dialetal própria do estado de São Paulo. Além disso, acredita-se que esses pontos do estado de Minas Gerais com presença de capucheta apontam para a confirmação de um possível falar paulista, adentrando a região do Triângulo Mineiro. Proposição já realizada por Zágari (2005) ao indicar a localização do falar paulista nas Minas Gerais ${ }^{16}$.

Ademais, salienta-se que ao buscar registros de capucheta em estudos sobre o vocabulário dos brinquedos em outras regiões do Brasil17, não foi cartografada a denominação em nenhum dos trabalhos. Estudos, como a tese de doutorado Brinquedos e brincadeiras infantis na área do falar baiano (RIBEIRO, 2012), as dissertações de mestrado, 0 falar amazônico: uma análise da proposta de Nascentes (1953) a partir de dados do Projeto ALiB (PORTILHO, 2013) e O léxico dos jogos e diversões infantis no corpus do Projeto ALiB: visitando o falar nordestino (SANTOS, 2018), não documentam a presença de capucheta para nomear a pipa sem varetas. A única menção que se faz à referida unidade léxica está indicada em Ribeiro (2012), ao informar que, "[...] No Projeto Mapa do Brincar (2009), há o registro de duas variantes para pipa (sem varetas) 63: a capuchetinha (Mutum - RO) e a capucheta (Valinhos - SP), para as quais está descrito o modo de confecção do brinquedo (cf. Anexo 05)". Nesse sentido, a indicação da denominação capuchetinha, em Rondônia, se dá apenas por referência consultada e não na conjuntura dos dados analisados.

Além das discussões sobre as ocorrências de capucheta, nas pesquisas que não contemplam o estado de São Paulo e imediações (RIBEIRO, 2012; PORTILHO, 2013; SANTOS, 2018), a inclinação no uso de zoomorfismos para nomear o brinquedo também se repete. Veja o quadro 5, que informa as denominações cartografadas pelas autoras nos diferentes estudos:

16 Essa constatação também é indicada na tese que analisa os dados do estado de São Paulo.

17 Recupera-se a informação de que essas pesquisas também foram estruturadas a partir do banco de dados do Projeto ALiB. 
Quadro 5. Quadro síntese das variantes cartografadas nos demais trabalhos sobre o léxico dos brinquedos

\begin{tabular}{|c|c|c|c|}
\hline Variações lexicais & $\begin{array}{c}\text { Brinquedos e } \\
\text { brincadeiras } \\
\text { infantis na área } \\
\text { do falar baiano } \\
\text { (RIBEIRO, 2012) }\end{array}$ & $\begin{array}{c}\text { 0 falar amazônico: } \\
\text { uma análise da } \\
\text { proposta de Nascentes } \\
\text { (1953) a partir de } \\
\text { dados do Projeto ALiB } \\
\text { (PORTILHO, 2013) }\end{array}$ & $\begin{array}{c}\text { 0 léxico dos jogos } \\
\text { e diversões infantis } \\
\text { no corpus do Projeto } \\
\text { ALiB: visitando o falar } \\
\text { nordestino (SANTOS, } \\
\text { 2018) }\end{array}$ \\
\hline Pipa & $X$ & $X$ & $X$ \\
\hline Papagaio & $X$ & $X$ & $X$ \\
\hline Arraia & $X$ & & $X$ \\
\hline Periquito & $X$ & & $X$ \\
\hline Avião/aviãozinho & $X$ & & $X$ \\
\hline Ratinho & $X$ & & \\
\hline Suru & $X$ & & \\
\hline Balão & $X$ & & \\
\hline Bicudo & $X$ & & \\
\hline Capota & $X$ & & \\
\hline Morcego & $X$ & & \\
\hline Arara & $X$ & & \\
\hline Curica/curiquinha & & & \\
\hline Coruja & & & \\
\hline chalopa & & & \\
\hline bolachinha & & & \\
\hline
\end{tabular}

Fonte: Elaboração própria18

O quadro 5 apresenta algumas denominações já registradas na região Sudeste do Brasil e também indica novos nomes para o brinquedo sem vareta.

Levando em conta a variedade de designativos para nomear a pipa sem varetas nos diferentes estudos, observa-se que, apesar de ser bastante diversificado e constar de um alto número de denominações, é possível dividi-las em ao menos duas áreas temáticas, são elas: animais e denominações genéricas. Entre essas denominações genéricas, poderia tratar-se de modo específico a objetos e/ou seres que consigam e/ou tenham o poder de voar.

18 Elaboração própria com base nos trabalhos referenciados. 
Informa-se que, nos diferentes trabalhos, os autores evidenciam algumas situações quando da obtenção das respostas. Por um lado, diferentes graus de dificuldade em receber alguma denominação para nomear esse brinquedo e dificuldade em distinguir a pipa com ou sem varetas e, por outro lado, grande segurança e descrição do objeto solicitado como confirmação de resposta. Verifique alguns comentários fornecidos pelos informantes que detalham características do objeto, após indicar o nome do brinquedo:

(01) INF.- Ah, aquela de lá é a... Eu brincava muito com isso. Capucheta. Acho que é isso mesmo./ INQ.- Às vezes a criança tá chorando, a mãe vai lá.../ INF.- É. Um papelzinho, amarra uma liinha, pronto! Levei tanto tombo com aquilo. Que ia correndo olhando pra trás e "tum"! (risos) (Ponto 174-Bragança Paulista /Informante 04).

(02) INF.- Capucheta [...]/ É aquele que é dobradinho? Ele é dobradinho, a linha sai assim ele é... Dá licença um poquinho.../INQ.- Pois não!/INF.- Dá licença. Ele é assim ó. Mais o menos assim... É capucheta!/INQ.- E o senhor nunca chamou isso de papagaio? /INF.- Não[...] INF.- Sempre foi maranhão e capucheta! (Ponto 173-Campinas/Informante 03).

Nota-se que esses informantes do Projeto ALiB, oriundos das coletas de dados no estado de São Paulo, conseguiram pontuar as diferenças entre a pipa com e sem varetas bem como defınir o objeto ${ }^{19}$. Essa situação ocorre de modo inverso em outras regiões do Brasil, como é o caso do estudo no Norte do país, em que Portilho (2013) registra que $35,2 \%$ dos informantes não souberam a resposta para a pergunta em análise.

\section{Considerações finais}

Este estudo teve, pois, como propósito analisar um recorte do léxico dialetal do português do Brasil, na perspectiva diatópica, ao examinar os dados para "um brinquedo parecido com a pipa, também feito de papel, mas sem varetas, que se empina ao vento por meio de uma linha" no estado de São Paulo. Como resultado, documentou-se a alta produtividade de capucheta em toda a unidade federativa, com registros na fala de diferentes faixas etárias e sexos, demonstrando a popularidade da variante nos diferentes segmentos da sociedade paulista.

Ainda sobre a capucheta, salienta-se que seu uso expressivo está restrito ao estado de São Paulo e sua presença também ocorre, de modo mais discreto, em algumas localidades de Minas Gerais e Paraná20, nas imediações do território paulista. Essa afırmação se

19 No caso específico do estado de São Paulo, indica-se como ausência de respostas três situações diferentes: esquecimento do nome ou desconhecimento do objeto; indicação, de modo acidental, por parte do inquiridor do nome e estabelecimento de relação com a pergunta anterior.

20 No Paraná, a denominação capucheta é registrada como ocorrência única. 
fundamenta na comparabilidade dos dados do estado de São Paulo ${ }^{21}$, com as demais variantes cartografadas para pipa sem varetas nos estudos sobre o léxico dos Jogos e Diversões Infantis que recobrem parte do país e que analisaram a área semântica a partir do Banco de Dados do Projeto ALiB, com especial atenção aos estudos nas Minas Gerais e na área delimitada no estudo do falar fluminense. Essa demarcação espacial do uso de capucheta, em São Paulo, representa um traço do léxico regional nitidamente marcado e que corrobora os estudos de Alencar (2018) e a possível delimitação de um falar paulista adentrando a região do Triângulo Mineiro, como já mencionado por Zágari (2005).

Quanto às demais denominações produtivas no estado de São Paulo, conclui-se que papagaio e pipa estão cartografados em todos os trabalhos referenciados sobre o léxico dos Jogos e Diversões Infantis, produzidos a partir dos dados do Projeto ALiB no país. Já a denominação arraia não figurou como resposta apenas no estudo sobre o falar amazônico, produzido por Portilho (2013).

De modo geral, ao analisar as denominações obtidas para a pipa sem vareta nos diferentes trabalhos discutidos, nota-se uma tendência a utilizar formas zoomórficas para nomear a brincadeira, além do uso de nomes que indicam objetos e/ou seres que têm a habilidade de voar.

Para concluir, a documentação dessas diferentes denominações se reflete muitas das vezes em questões histórico-sociais das localidades em que são registradas e que normalmente o homem não consegue controlar, entre elas, possível "[...] referência a influências, principalmente de natureza física, que escapam à vontade do homem" (SAPIR, 1969, p. 45). Entre outros fatores, cita-se como exemplo, algumas brincadeiras que parecem caracterizar as diferentes épocas do ano. Nesse sentido, "a sazonalidade de certas brincadeiras, ainda pouco documentada e ainda menos compreendida, sugere a sensibilidade da criança para os ritmos e ciclos da natureza e do ambiente social" (CARVALHO; PONTES, 2011, p. 24).

Para finalizar, neste estudo fica evidente que, independente das motivações, o modo de nomear um brinquedo pode refletir na relação que o homem constrói com esses objetos e também com o espaço que se encontra geograficamente, o que se expressa no léxico da língua que é o "[...] que mais nitidamente reflete o ambiente físico e social dos falantes" (SAPIR, 1969, p. 45). No caso da denominação capucheta, ela denota a preferência lexical de uma determinada população e caracteriza a "pipa sem varetas" para boa parte dos moradores do estado de São Paulo, no início do século XXI.

21 Além disso, pode-se considerar o fato de alguns informantes descreverem a capucheta com exatidão e também a informação registrada no dicionário informal (www. dicionarioinformal.com.br) que define capucheta como: "No Brasil, é o termo usado na Região de São Paulo para definir uma pipa feita com jornal, sem varetas, apenas papel e linha". 


\section{REFERÊNCIAS}

ALENCAR, B. A. O Léxico de brinquedos e brincadeiras infantis no estado de São Paulo. 2018. Tese (Doutorado em Letras) - Universidade Federal do Mato Grosso do Sul, Três Lagoas, 2018.

BENJAMIN, W. Reflexões sobre a criança, o brinquedo e a educação. 2. ed. Rio de Janeiro: Editora 34, 2009.

BIDERMAN, M. T. C. Dimensões da Palavra. Filologia e Língua Portuguesa, São Paulo, Humanitas Publicações/FFLCH/USP, n. 02, p. 81-118, 1998.

CARDOSO, S. A. M. Geolinguística: tradição e modernidade. São Paulo: Parábola, 2010.

CARDOSO, S. A. M. et al. Atlas linguístico do Brasil. v. 2 (Cartas linguísticas). Londrina: EdUEL, 2014.

CARVALHO, A. M. A.; PONTE, F. A. R. Brincadeira é Cultura. In: CARVALHO, A. M. A.; MAGALHÃES, C. M. C.; PONTES, F. A. R.; BICHAR, I. D. Brincadeira e cultura: viajando pelo Brasil que brinca. v. 1: o Brasil que brinca. São Paulo. Casa do Psicólogo, 2011. p. 15-30.

COMITÊ NACIONAL DO PROJETO ALiB. Atlas Linguístico do Brasil: Questionários 2001. 2. ed. Londrina: EdUEL, 2001.

D'ANUNCIAÇÃO, E. S. Registrando o léxico dos brinquedos e brincadeiras infantis em Minas Gerais. 2016. Monografia (Graduação em Letras) - Universidade Federal da Bahia, Salvador, 2016.

DICIONÁRIO INFORMAL. Disponível em: www.dicionarioinformal.com.br. Acesso em: 20 set. 2018 .

FOLHA DE SÃO PAULO. Projeto mapa do Brincar Folha On line. Disponível em: http:// www1.folha.uol.com.br/folha/treinamento/mapadobrincar/. Acesso em: 20 fev. 2018.

PORTILHO, D. A. S. O falar amazônico: uma análise da proposta de Nascentes (1953) a partir de dados do Projeto ALiB. 2013. Dissertação (Mestrado em Estudos de Linguagens) - Universidade Federal do Mato Grosso do Sul, Campo Grande, 2013. 
RIBEIRO, S. S. C. Brinquedos e brincadeiras infantis na área do "falar baiano". 2012. Tese (Doutorado em Letras) - Universidade Federal da Bahia, Salvador, 2012.

SAPIR, E. Linguística como ciência. Rio de Janeiro: Ed. Livraria Acadêmica, 1969.

SANTOS, L. A. dos. Brincando pelos caminhos do falar fluminense. 2016. Dissertação (Mestrado em Língua e Cultura) - Programa de Pós-Graduação em Língua e Cultura, Instituto de Letras, Universidade Federal da Bahia, Salvador, 2016.

SANTOS, G. F. da S. O léxico dos jogos e diversões infantis no corpus do Projeto ALiB: visitando o falar nordestino. 2018. Dissertação (Mestrado em Língua e Cultura) Universidade Federal da Bahia, Salvador, 2018.

ZÁGARI, M. R. L. Os falares mineiros: esboço de um Atlas Lingüístico de Minas Gerais. In: AGUILERA, V. de A. (org.). A Geolingüística no Brasil - trilhas seguidas, caminhos a percorrer. v. 1. Londrina: EdUEL, 2005. p. 45-72. 